\title{
Plasma suíno e ovo inteiro em rações de leitões sobre desempenho na fase inicial e efeito residual até a terminação
}

\author{
Swine plasma and whole egg in ration for weaner pigs in performance in initial phase and \\ residual effect until finishing phase
}
Maria Cristina THOMAZ ${ }^{1}$; Melissa Izabel HANNAS ${ }^{2}$; Rodolfo Nascimento KRONKA ${ }^{1}$; Fernanda Marcussi TUCCI ${ }^{3}$; Antônio João SCANDOLERA ${ }^{4}$; Maria Marta LODDI ; Fábio Enrique Lemos BUDINOO $^{6}$

\author{
${ }^{1}$ Faculdade de Ciências Agrárias e Veterinárias da Universidade Estadual Paulista, Jaboticabal-SP, Brasil \\ ${ }^{2}$ Alltech do Brasil, Curitiba-PR, Brasil \\ ${ }^{3}$ MAPA, Brasília-DF, Brasil \\ ${ }^{4}$ Universidade Federal do Paraná, Curitiba-PR, Brasil \\ ${ }^{5}$ Universidade Estadual de Ponta Grossa, Ponta Grossa-PR, Brasil \\ ${ }^{6}$ Instituto de Zootecnia/APTA/SAA, Nova Odessa-SP, Brasil
}

\begin{abstract}
Resumo
Foram utilizados 64 leitões distribuídos em oito tratamentos: ração com leite em pó (LP), três rações com níveis crescentes de plasma suíno (PS), três rações com níveis crescentes de ovo inteiro (OI) e ração com alto nível de farelo de soja (FS). Avaliou-se o ganho diário de peso (GDP), o consumo diário de ração (CDR) e a conversão alimentar (CA). Os animais que consumiram ração FS apresentaram média de GDP superior aos demais tratamentos, dos 35 aos 48 dias de idade. O aumento dos níveis de PS proporcionou redução linear do GDP, dos 21 aos 35 e dos 35 aos 48 dias de idade e do CDR dos 48 aos 138 dias de idade e piora linear da CA, dos 21 aos 35 dias de idade. Considerando o período da desmama até à terminação as rações inicias podem conter PS e OI, substituindo parcialmente à PB do leite em pó em 25 e $45 \%$, respectivamente.
\end{abstract}

Palavras-chave: Farelo de soja. Fontes proteicas. Ganho de peso. Leite em pó. Leitões.

\begin{abstract}
Were used 64 weaned pigs, distributed in eight treatments: ration with skim milk (SM), three rations with crescent levels of swine plasma (SP), three rations with whole egg (WE) and a ration with high inclusion of soybean meal (SB). Daily weight gain (DWG), daily feed intake (DFI) and feed conversion (FC) were evaluated. The animals that consumed ration SB have the mean of DWG higher that other treatments, and inferior FC, from 35 to 48 days of age. The crescent levels of SP promoted linear reduction in DWG, from 21 to 35, and from 35 to 48 days of age, in DFI from 48 to 138 days of age and linear increased in FC from 21 to 35 of age. Considering the weaned phase until finishing, initial rations can be formulated with SP and WE substituted partially the CP of skim milk in 25 and $45 \%$, respectively.
\end{abstract}

Keywords: Piglets. Protein sources. Skim milk. Soybean meal. Weight gain.

\section{Introdução}

A mudança abrupta da alimentação láctea para a ração sólida, quando leitões são desmamados, está associada a um período de não alimentação e, como resultado, a parada no crescimento tem impacto negativo no desempenho subsequente, desse modo, a nutrição pós-desmama é essencial para que os suínos possam expressar seu máximo potencial genético.

As pesquisas sobre nutrição de leitões vêm sendo direcionadas para avaliar outras fontes de proteína que possam substituir ou serem fornecidas em combinação com a proteína do leite ${ }^{1}$. Dentre os ingredientes que vêm sendo intensamente estudados, os produtos de origem animal e derivados do sangue, como plas-

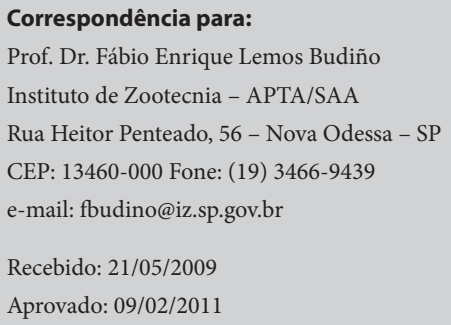


ma e hemácias, têm-se apresentado eficientes em melhorar o desempenho dos leitões na fase inicial ${ }^{2}$.

No passado, os produtos do sangue na forma de farinha eram processados através de tratamentos com altas temperaturas e tempo prolongado, o que permitia a secagem do produto e a eliminação de contaminação biológica. Entretanto, estes processamentos resultavam em produtos com qualidade inconsistente, em relação a digestibilidade e solubilidade, e com diferentes níveis de contaminação por pêlos, urina e material $\mathrm{fecal}^{3}$, o que limitava a utilização nas rações animais.

A introdução do método de processamento por spray-drier melhorou a qualidade dos produtos derivados do sangue usados nas rações, possibilitando a manutenção da integridade dos componentes funcionais das proteínas e preservando a digestibilidade dos aminoácidos ${ }^{4}$. Permitiu também a utilização do ovo inteiro, uma vez que, após desidratado, este pode ser facilmente armazenado e adicionado às rações animais.

Os resultados de pesquisas indicam que o plasma suíno proporciona melhora no desempenho dos leitões, quando utilizado em rações pós-desmama, sendo a resposta dependente da qualidade do produto, do seu nível de inclusão, da idade e do peso dos leitões, status sanitário e ambiente dentro da instalação ${ }^{4}$.

A utilização de coprodutos da indústria torna-se cada vez mais importante, trazendo alternativas que reduzem o custo da produção final. No entanto, os resultados da utilização destas matérias-primas nas rações nem sempre permanecem até o final da fase de terminação dos animais, levando os responsáveis pelos sistemas de produção questionarem a importância de utilização das rações complexas na fase inicial.

O objetivo do presente trabalho foi verificar o uso do plasma suíno e ovo inteiro em substituição ao leite em pó, e ração com alto nível de farelo de soja sobre a incidência de diarreia, desempenho dos leitões na fase inicial e efeito residual dos tratamentos sobre o desempenho até à terminação.

\section{Material e Método}

O experimento foi conduzido no Setor de Suinocultura do Departamento de Zootecnia da Faculdade de Ciências Agrárias e Veterinárias da Universidade Estadual Paulista, Campus de Jaboticabal.

Foram utilizados 64 leitões (Camborough $22 \mathrm{X}$ AGPIC 419), desmamados aos 21 dias de idade, distribuídos em delineamento em blocos casualizados com oito tratamentos, oito repetições e um animal por unidade experimental. Na formação dos blocos foram considerados peso inicial e sexo.

Os animais foram alojados em dois galpões cada um contendo 36 baias individuais de 1,50 $\mathrm{m} \mathrm{x} \mathrm{1,70}$ $m$ equipadas com bebedouro tipo vaso comunicante $\mathrm{e}$ comedouro semiautomático, com cortinas nas laterais da instalação.

As rações experimentais, dos 21 aos 35 e dos 35 aos 48 dias de idade, foram formuladas para atenderem ou excederem as recomendações do $\mathrm{NRC}^{5}$ (Tabelas 1 e 2) e para a formulação das rações foram utilizados os valores de proteína bruta, sódio, cálcio e energia metabolizável do plasma suíno (PS) e do ovo inteiro (OI), obtidos por Hannas et al. ${ }^{6}$, dos aminoácidos do PS, fornecidos pelo fabricante $\left(\mathrm{Hemoprot}^{\circledR}\right)$, do OI, citados no Egg Products ${ }^{7}$ e do leite, farelo de soja, milho e lactose citados no NRC 5 .

No período 1, dos 21 aos 35 dias de idade dos leitões, foram fornecidas oito rações: 1- controle positivo contendo leite em pó desnatado (LP) como principal fonte de proteína; 2- 2,95\% de PS; 3- 5,90\% de PS; 4- 8,94\% de PS; 5- 2,54\% de OI; 6- 5,08\% de OI; 7-7,62\% de OI e 8- controle negativo contendo farelo de soja (FS) como principal fonte de proteína. O PS e o OI foram incluídos nas rações, substituindo 25,50 e 75\% e 15, 30 e 45\% da proteína bruta do leite em pó da ração LP, respectivamente. 
Tabela 1 - Composição centesimal e calculada das rações experimentais do período 1 (21 aos 35 dias de idade dos leitões)

\begin{tabular}{|c|c|c|c|c|c|c|c|c|}
\hline Ingredientes & LP & $\begin{array}{c}\text { PS } \\
25 \% \text { * }\end{array}$ & $\begin{array}{c}\text { PS } \\
50 \% \text { * }\end{array}$ & $\begin{array}{c}\text { PS } \\
75 \% \text { * }\end{array}$ & $\begin{array}{c}\text { OI } \\
15 \% \text { * }\end{array}$ & $\begin{array}{c}\text { OI } \\
30 \% \text { * }\end{array}$ & $\begin{array}{c}\text { OI } \\
45 \% \text { * }\end{array}$ & FS \\
\hline Leite em pó & 23,502 & 17,474 & 11,433 & 5,300 & 20,485 & 17,468 & 14,452 & 8,743 \\
\hline Plasma suíno & - & 2,950 & 5,906 & 8,940 & - & - & - & - \\
\hline Ovo inteiro & - & - & - & - & 2,540 & 5,080 & 7,620 & - \\
\hline Lactose & 2,343 & 5,483 & 8,629 & 11,83 & 3,914 & 5,485 & 7,056 & 10,030 \\
\hline Milho & 43,106 & 43,46 & 43,813 & 44,00 & 40,962 & 38,818 & 36,675 & 38,413 \\
\hline Calcário & 0,092 & 0,495 & 0,899 & 1,300 & 0,120 & 0,148 & 0,176 & 0,124 \\
\hline Fosfato bicálcico & 1,769 & 1,412 & 1,054 & 0,720 & 1,851 & 1,932 & 2,013 & 2,213 \\
\hline Inerte (Caulim) & 1,100 & 0,970 & 0,840 & 0,820 & 2,059 & 3,017 & 3,974 & - \\
\hline L-lisina $\mathrm{HCl}$ & 0,391 & 0,413 & 0,435 & 0,460 & 0,398 & 0,405 & 0,412 & 0,511 \\
\hline Dl-metionina & 0,225 & 0,242 & 0,259 & 0,276 & 0,203 & 0,182 & 0,161 & 0,264 \\
\hline L-treonina & 0,206 & 0,200 & 0,194 & 0,187 & 0,203 & 0,201 & 0,198 & 0,251 \\
\hline L-triptofano & 0,027 & 0,017 & 0,007 & 0,000 & 0,029 & 0,031 & 0,033 & 0,032 \\
\hline Sal & 0,330 & 0,200 & 0,071 & 0,000 & 0,355 & 0,381 & 0,407 & 0,573 \\
\hline Açúcar & 1,000 & 1,000 & 1,000 & 1,000 & 1,000 & 1,000 & 1,000 & 1,000 \\
\hline Antioxidante & 0,040 & 0,040 & 0,040 & 0,040 & 0,040 & 0,040 & 0,040 & 0,040 \\
\hline Farelo de soja & 18,00 & 18,00 & 18,00 & 18,00 & 18,00 & 18,00 & 18,00 & 30,00 \\
\hline Suplem. vitamínico ${ }^{* *}$ & 0,600 & 0,600 & 0,600 & 0,600 & 0,600 & 0,600 & 0,600 & 0,600 \\
\hline Suplem. mineral ${ }^{* * *}$ & 0,240 & 0,240 & 0,240 & 0,240 & 0,240 & 0,240 & 0,240 & 0,240 \\
\hline Óleo vegetal & 6,000 & 6,000 & 6,000 & 6,000 & 6,000 & 6,000 & 6,000 & 6,000 \\
\hline Óxido de zinco & 0,220 & 0,220 & 0,220 & 0,220 & 0,220 & 0,220 & 0,220 & 0,220 \\
\hline Carbonato de sódio & 0,811 & 0,585 & 0,359 & 0,069 & 0,781 & 0,752 & 0,723 & 0,746 \\
\hline Total & 100,0 & 100,0 & 100,0 & 100,0 & 100,0 & 100,0 & 100,0 & 100,0 \\
\hline \multicolumn{9}{|l|}{ Composição calculada } \\
\hline $\mathrm{EM}(\mathrm{kcal} / \mathrm{kg})$ & 3.500 & 3.500 & 3.500 & 3.495 & 3.500 & 3.500 & 3.500 & 3.444 \\
\hline Cálcio (\%) & 0,850 & 0,850 & 0,850 & 0,853 & 0,850 & 0,850 & 0,850 & 0,850 \\
\hline Fibra (\%) & 2,192 & 2,184 & 2,175 & 2,163 & 2,136 & 2,081 & 2,026 & 2,833 \\
\hline Fósforo total (\%) & 0,800 & 0,800 & 0,800 & 0,806 & 0,800 & 0,800 & 0,800 & 0,800 \\
\hline Gordura (\%) & 7,925 & 7,953 & 7,981 & 8,002 & 8,653 & 9,382 & 10,11 & 7,903 \\
\hline Lactose (\%) & 14,00 & 14,00 & 14,00 & 14,00 & 14,00 & 14,00 & 14,00 & 14,00 \\
\hline Proteína (\%) & 20,50 & 20,50 & 20,50 & 20,51 & 20,50 & 20,50 & 20,05 & 20,50 \\
\hline Lisina (\%) & 1,600 & 1,600 & 1,600 & 1,600 & 1,600 & 1,600 & 1,600 & 1,600 \\
\hline Metionina+cistina (\%) & 0,900 & 0,900 & 0,900 & 0,900 & 0,900 & 0,900 & 0,900 & 0,900 \\
\hline Metionina (\%) & 0,622 & 0,605 & 0,587 & 0,569 & 0,606 & 0,592 & 0,577 & 0,590 \\
\hline Treonina (\%) & 1,020 & 1,020 & 1,020 & 1,020 & 1,020 & 1,020 & 1,020 & 1,020 \\
\hline Triptofano (\%) & 0,284 & 0,284 & 0,284 & 0,287 & 0,284 & 0,284 & 0,284 & 0,284 \\
\hline Sódio (\%) & 0,630 & 0,630 & 0,630 & 0,630 & 0,630 & 0,630 & 0,630 & 0,630 \\
\hline Cloro (\%) & 0,460 & 0,460 & 0,460 & 0,497 & 0,460 & 0,460 & 0,460 & 0,460 \\
\hline Potássio (\%) & 0,864 & 0,769 & 0,674 & 0,577 & 0,819 & 0,775 & 0,731 & 0,830 \\
\hline
\end{tabular}

LP (leite em pó); PS (plasma suíno); OI (ovo inteiro); FS (farelo de soja);

* \% de substituição da proteína do leite em pó da ração LP;

** suplemento vitamínico Nutre-suinicial (Nutremix) - Níveis de garantia por kg de produto: vit A 4.000.000 U.I, vit D-3 1.000.000 U.I, vit E $10.000 \mathrm{mg}$, vit K-3 $3.000 \mathrm{mg}$, vit $\mathrm{B}_{1} 9.000 \mu \mathrm{g}$, vit $\mathrm{B}_{2} 3.800 \mathrm{mg}$, biotina $40 \mathrm{mg}$, pantotenato de cálcio $6.000 \mathrm{mg}$, niacina $14.000 \mathrm{mg}$, colina 100 g, antibiótico $150 \mathrm{~g}$, antioxidante $60 \mathrm{~g}$, veículo q.s.p. $1.000 \mathrm{~g}$. ${ }^{* *}$ suplemento mineral Minermix suínos (Nutremix) - Níveis de garantia por $\mathrm{kg}$ de produto: Ferro $40.000 \mathrm{mg}$, Cobre $35.000 \mathrm{mg}$, Manganês $20.000 \mathrm{mg}$, Zinco $40.000 \mathrm{mg}$, Cobalto $360 \mathrm{mg}$, Iodo $840 \mathrm{mg}$, Selênio $120 \mathrm{mg}$, veículo q.s.p $1.000 \mathrm{~g}$. 
Tabela 2 - Composição centesimal e calculada das rações experimentais fornecidas no período 2 ( 35 aos 48 dias de idade dos leitões)

\begin{tabular}{|c|c|c|c|c|}
\hline Ingredientes & LP & $2,59 \%$ PS & $2,54 \%$ OI & FS \\
\hline Leite em pó & 10,584 & 5,200 & 7,567 & 5,007 \\
\hline Plasma suíno & - & 2,590 & - & - \\
\hline Ovo inteiro & - & - & 2,540 & - \\
\hline Lactose & 1,779 & 4,590 & 3,350 & 5,493 \\
\hline Milho & 51,268 & 51,764 & 49,125 & 49,345 \\
\hline Calcário & 0,202 & 0,560 & 0,230 & 0,212 \\
\hline Fosfato bicálcico & 2,083 & 1,770 & 2,164 & 2,253 \\
\hline Inerte (Caulim) & 1,133 & 0,853 & 2,089 & 0,021 \\
\hline L-lisina $\mathrm{HCl}$ & 0,439 & 0,467 & 0,446 & 0,484 \\
\hline Dl-metionina & 0,203 & 0,220 & 0,182 & 0,218 \\
\hline L-treonina & 0,208 & 0,204 & 0,205 & 0,225 \\
\hline L-triptofano & 0,032 & 0,024 & 0,034 & 0,034 \\
\hline Sal & 0,417 & 0,305 & 0,440 & 0,509 \\
\hline Antioxidante (Banox) & 0,060 & 0,060 & 0,060 & 0,06 \\
\hline Farelo de soja & 25,428 & 25,428 & 25,428 & 30,000 \\
\hline Suplem. Vitamínico * & 0,400 & 0,400 & 0,400 & 0,400 \\
\hline Suplem. Mineral ${ }^{* *}$ & 0,240 & 0,240 & 0,240 & 0,240 \\
\hline Óleo vegetal & 5,000 & 5,000 & 5,000 & 5,000 \\
\hline Carbonato de sódio & 0,524 & 0,325 & 0,500 & 0,499 \\
\hline Total & 100,0 & 100,0 & 100,0 & 100,0 \\
\hline \multicolumn{5}{|l|}{ Composição química calculada } \\
\hline Energia Metabolizável (kcal/kg) & 3.400 & 3.405 & 3.400 & 3.400 \\
\hline Cálcio (\%) & 0,850 & 0,851 & 0,850 & 0,850 \\
\hline Fósforo Total (\%) & 0,800 & 0,800 & 0,800 & 0,800 \\
\hline Fibra (\%) & 2,809 & 2,806 & 2,754 & 3,049 \\
\hline Gordura (\%) & 7,337 & 7,369 & 8,065 & 7,320 \\
\hline Lactose (\%) & 7,000 & 7,006 & 6,999 & 7,000 \\
\hline Proteína (\%) & 20,000 & 19,994 & 19,999 & 20,000 \\
\hline Lisina (\%) & 1,500 & 1,504 & 1,500 & 1,500 \\
\hline Metionina+cistina (\%) & 0,848 & 0,849 & 0,848 & 0,848 \\
\hline Metionina (\%) & 0,541 & 0,527 & 0,526 & 0,529 \\
\hline Treonina (\%) & 0,965 & 0,965 & 0,965 & 0,965 \\
\hline Triptofano (\%) & 0,274 & 0,274 & 0,274 & 0,274 \\
\hline Potássio (\%) & 0,817 & 0,733 & 0,772 & 0,804 \\
\hline Sódio (\%) & 0,480 & 0,480 & 0,481 & 0,480 \\
\hline Cloro (\%) & 0,390 & 0,390 & 0,389 & 0,390 \\
\hline
\end{tabular}


No período 2, dos 35 aos 48 dias de idade dos leitões, os animais foram submetidos a quatro tratamentos: 1- controle positivo com leite em pó; 2- 2,59\% de PS; 3-2,54\% de OI e 4- controle negativo com farelo de soja, respeitando-se a principal fonte de proteína fornecida no primeiro período, de modo que os animais que consumiram ração LP na período 1, continuaram recebendo ração com leite em pó como principal fonte de proteína na período 2. Os leitões que receberam o controle negativo FS, no período 1 , foram mantidos em tratamento com alto nível de farelo de soja. Os leitões que consumiram rações com diferentes níveis de PS ou OI foram submetidos a tratamento contendo um nível mínimo de PS ou OI, como manutenção da fonte de proteína de origem animal.

A partir dos 48 dias até atingirem 138 dias de idade, todos os animais receberam as mesmas rações, formuladas à base de milho e farelo de soja, para atender ou exceder as recomendações do $\mathrm{NRC}^{5}$.

Os animais, a ração fornecida e as sobras de ração foram pesados semanalmente, dos 21 aos 62 dias de idade dos leitões, e posteriormente a cada 15 dias até os animais atingirem $93,0 \mathrm{~kg}$ de peso vivo para determinação do ganho diário de peso (GDP) em g/dia, consumo diário de ração (CDR) em g/dia e conversão alimentar (CA) que foram avaliados nos seguintes períodos: período 1 - dos 21 aos 35 dias de idade; período 2 - dos 35 aos 48 dias de idade e período 3 - dos 48 aos 138 dias de idade.

Os resultados dos parâmetros de desempenho foram submetidos à análise de variância e as médias dos fatores decompostos em contrastes ortogonais ao nível de 5\% de probabilidade. Para as análises estatísticas o tratamento LP foi considerado como nível $0 \%$ de PS e nível 0\% de OI, totalizando, então, nove tratamentos e decomposição de oito contrastes ortogonais: 1 : farelo de soja vs demais tratamentos; 2 : níveis de PS vs níveis de OI; 3: regressão linear do PS; 4: regressão quadrática do PS; 5: regressão cúbica do PS; 6 : regressão linear do OI; 7: regressão quadrática do OI e 8: regressão cúbica do OI. Para a realização das análises estatísticas foi utilizado o programa computacional SAS - PROC GLM ${ }^{8}$.

\section{Resultados e Discussão}

As médias do peso vivo (PV), ganho diário de peso (GDP), consumo diário de ração (CDR) e conversão alimentar (CA) dos leitões consumindo rações com LP, PS, OI e FS na fase inicial, nos períodos dos 21 aos 35 e dos 48 aos 138 dias de idade, estão apresentadas na tabela 3.

\section{Período 1 (21 aos 35 dias de idade)}

Não foi observada diferença significativa $(P>0,05)$ para os contrastes $1,2,4,5,6,7$, e 8 sobre o GDP, CDR e CA dos leitões. O desempenho dos leitões consumindo ração FS foi semelhante à média daqueles submetidos aos demais tratamentos.

Quando observado o GDP dos animais consumindo ração FS, em valores absolutos, estes foram 18,73\% inferiores aqueles consumindo ração LP. Estes resultados estão de acordo com Friesen et al. ${ }^{9}$ e Soares et al. ${ }^{10}$, os quais observaram que a utilização de altos níveis de farelo de soja influenciou negativamente o desempenho dos leitões, quando comparados aos animais consumindo ração com proteína à base de leite em pó.

$\mathrm{O}$ consumo semelhante de ração entre os animais arraçoados com LP e aqueles com FS e a pior CA daqueles alimentados com a ração FS sugere que a utilização dos nutrientes da soja foi menos eficiente. Tal observação corrobora os relatos de Tokach et al. ${ }^{11} \mathrm{e}$ Mahan e Lepine ${ }^{12}$ que verificaram que leitões recémdesmamados digerem com mais eficiência as proteínas do leite do que os carboidratos complexos e proteínas de origem vegetal. Todavia, os resultados discordam do relato de Soares et al. ${ }^{10}$, que observaram diferença no GDP e no CDR entre leitões consumindo rações com leite em pó e farelo de soja, dos 21 aos 35 dias de idade, sendo o menor GDP justificado pela redução no CDR dos leitões consumindo rações com farelo de soja. 
Tabela 3 - Médias de GDP (g/dia), CDR (g/dia) e CA dos leitões consumindo rações com LP, PS, OI e FS, nos períodos 1, 2 e 3, dos 21 aos 35 (P1), dos 35 aos 48 (P2), e dos 48 aos 138 dias de idade $(\mathrm{P} 3)$, respectivamente

\begin{tabular}{|c|c|c|c|c|c|c|c|c|c|c|}
\hline \multicolumn{2}{|c|}{ Períodos } & \multirow{2}{*}{$\begin{array}{c}\text { LP } \\
0,267\end{array}$} & \multirow{2}{*}{$\begin{array}{c}\text { PS } \\
25 \%^{*} \\
0,276\end{array}$} & \multirow{2}{*}{$\begin{array}{c}\text { PS } \\
50 \%^{*} \\
0,190\end{array}$} & \multirow{2}{*}{$\begin{array}{c}\text { PS } \\
75 \%^{*} \\
0,169\end{array}$} & \multirow{2}{*}{$\begin{array}{c}\text { OI } \\
15 \%^{*} \\
0,213\end{array}$} & \multirow{2}{*}{$\begin{array}{c}\text { OI } \\
30 \% *\end{array}$} & \multirow{2}{*}{$\begin{array}{c}\text { OI } \\
45 \%^{*}\end{array}$} & \multirow{2}{*}{$\begin{array}{c}\text { FS } \\
0,217\end{array}$} & \multirow{2}{*}{$\begin{array}{c}\begin{array}{c}\text { CV } \\
(\%)\end{array} \\
33,15\end{array}$} \\
\hline P 1 & $\mathrm{GDP}^{\mathrm{C} 3}$ & & & & & & & & & \\
\hline & CDR & 0,312 & 0,352 & 0,290 & 0,268 & 0,285 & 0,307 & 0,294 & 0,292 & 20,62 \\
\hline & $\mathrm{CA}^{\mathrm{C} 3}$ & 1,26 & 1,27 & 1,54 & 1,63 & 1,57 & 1,27 & 1,32 & 1,53 & 24,33 \\
\hline \multirow{3}{*}{ P 2} & $\mathrm{GDP}^{\mathrm{C} 1, \mathrm{C} 3}$ & 0,486 & 0,459 & 0,433 & 0,395 & 0,484 & 0,520 & 0,414 & 0,569 & 20,66 \\
\hline & CDR & 0,650 & 0,672 & 0,617 & 0,565 & 0,643 & 0,659 & 0,565 & 0,676 & 17,27 \\
\hline & $\mathrm{CA}^{\mathrm{Cl}}$ & 1,35 & 1,50 & 1,43 & 1,52 & 1,40 & 1,28 & 1,39 & 1,19 & 17,93 \\
\hline \multirow{3}{*}{ P 3} & GDP & 0,880 & 0,880 & 0,877 & 0,848 & 0,888 & 0,864 & 0,884 & 0,860 & 6,52 \\
\hline & $\mathrm{CDR}^{\mathrm{C} 3}$ & 2,175 & 2,130 & 2,145 & 2,039 & 2,160 & 2,112 & 2,099 & 2,140 & 5,39 \\
\hline & CA & 2,47 & 2,42 & 2,44 & 2,41 & 2,44 & 2,44 & 2,37 & 2,48 & 4,84 \\
\hline
\end{tabular}

LP (leite em pó); PS (plasma suíno); OI (ovo inteiro); FS (farelo de soja);

*\% de substituição da PB do LP da ração LP.

Contrastes testados:

C1: FS vs demais; C2: Níveis de PS vs níveis de OI; C3: Regressão (Reg) linear PS; C4: Reg quadrática PS; C5: Reg cúbica PS; C6: Reg linear OI; C7: Reg quadrática OI; C8: Reg cúbica OI.

Efeito significativo dos contrastes ao nível de $5 \%$ de probabilidade $(\mathrm{P}<0,05)$ : ${ }^{\mathrm{C} 1}-$ Contraste 1 : FS vs demais tratamentos; ${ }^{\mathrm{C} 2}$ - Contraste 2: níveis de PS vs níveis de OI; ${ }^{\mathrm{C} 3}$ - Contraste 3: reg linear PS.

A correção dos níveis de lactose (Tabela 1) também pode ter influenciado positivamente os resultados da utilização do alto nível de farelo de soja (30\%) na fase inicial, pois segundo Nessmith et al. ${ }^{13}$, o aumento do teor de lactose na ração possibilitou a redução da quantidade de plasma e aumento da percentagem de farelo de soja nas rações de leitões após a desmama.

Não foi observada diferença significativa $(\mathrm{P}>0,05)$ entre as médias de GDP, CDR e CA dos leitões que consumiram rações com níveis crescentes de PS e aqueles consumindo níveis crescentes de OI, concordando com os trabalhos de Nessmith et al. ${ }^{14}$, que observaram que a adição de $6 \%$ do ovo pode substituir em 3,5\% o plasma na ração, não afetou o desempenho dos suínos. Harmon, Latour e Durst ${ }^{15}$ e Figueiredo ${ }^{16}$ também verificaram resultados semelhantes no desempenho dos leitões, quando o ovo foi utilizado nas rações iniciais, em substituição total à proteína do plasma animal, indicando que o aproveitamento dos nutrientes destas fontes proteicas foi semelhante.

Uma vez que a substituição parcial da proteína bruta (PB) do LP pela PB do PS e/ou do OI proporcionou desempenho médio semelhante, deve-se considerar os resultados da análise dos contrastes dos níveis de PS e de OI para uma substituição adequada da PB do LP na ração de leitões na fase inicial.

Foi observado efeito linear dos níveis de PS sobre o GDP $(\mathrm{P}<0,01)$ e CA $(\mathrm{P}<0,017)$ e tendência para efeito significativo sobre o CDR $(\mathrm{P}<0,06)$. O GDP dos leitões reduziu-se linearmente com o aumento dos níveis de PS na ração, conforme a equação $\mathrm{Y}_{\mathrm{CDR}}=$ $0,2790-0,001483 \mathrm{X}\left(\mathrm{R}^{2}=0,86\right)$, enquanto a conversão alimentar (CA) piorou linearmente, conforme equação $\mathrm{Y}_{\mathrm{CA}}=1,12372+0,005314 \mathrm{X}\left(\mathrm{R}^{2}=0,91\right)$ (Figura 1). Porém, os animais que consumiram ração com o PS substituindo 25\% da PB do LP apresentaram GDP e CDR em valores absolutos 3,37 e 12,82\% superiores, respectivamente, àqueles que consumiram ração LP. A substituição de 50 e $75 \%$ da PB do LP pela PB do PS proporcionou a redução do CDR em valores absolutos em 7,05 e $14,10 \%$, respectivamente.

Os resultados da utilização do PS na ração discordam daqueles observados em diversos trabalhos citados na literatura, os quais apontam maiores GDP e 


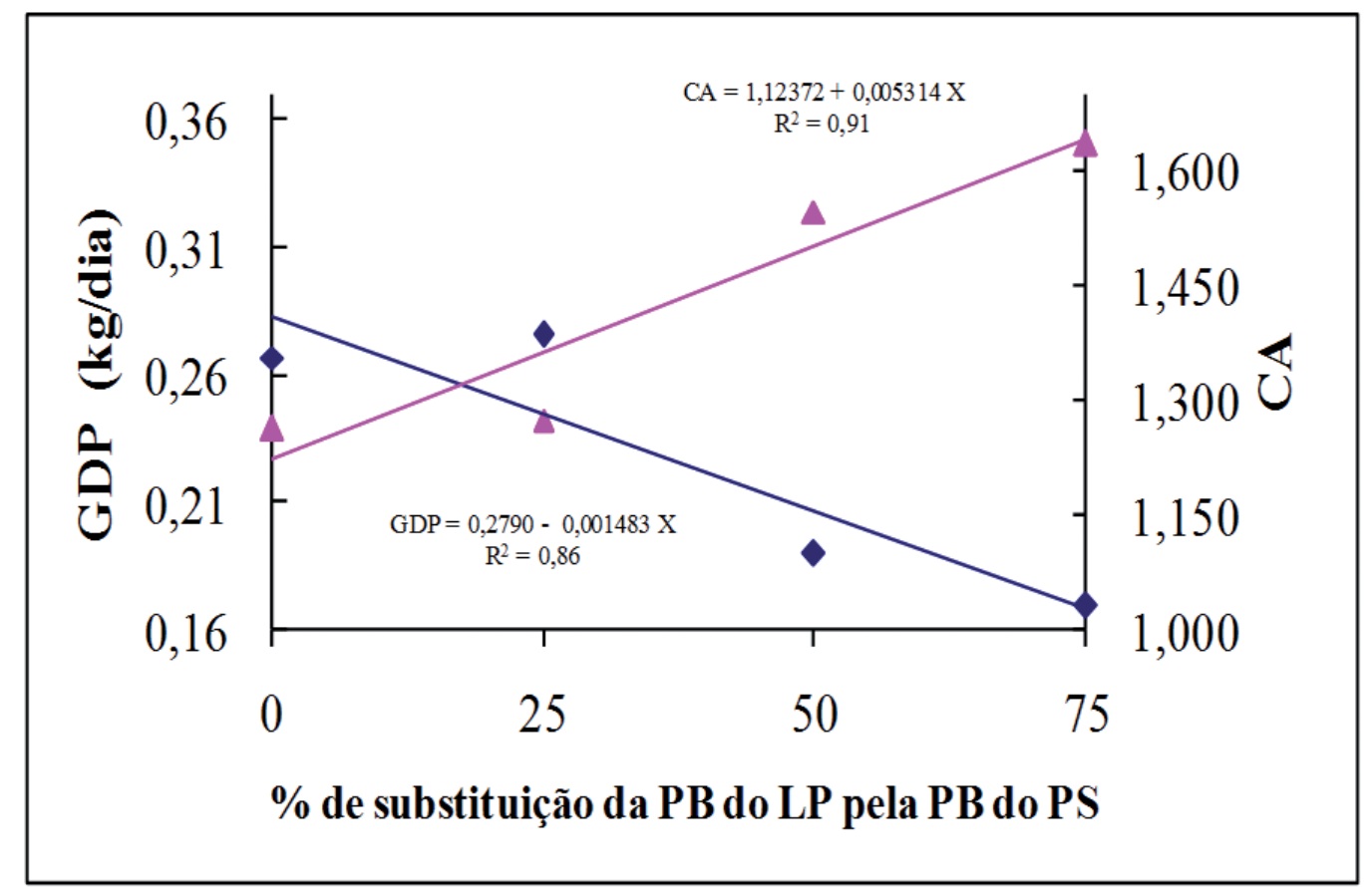

Figura 1 - Níveis de substituição da proteína do LP pela proteína do PS, dos 21 aos 35 dias de idade, sobre o GDP e CA dos leitões dos 21 aos 35 dias de idade

CDR nos animais quando o plasma foi utilizado em diferentes níveis, em substituição ao milho, farelo de soja e soro de leite $\mathrm{e}^{17,18}$ ou em substituição ao leite em pó $^{19,13}$.

Os resultados verificados também dos obtidos por Touchette et al. ${ }^{20}$ e Bergstrom et al. ${ }^{21}$, que verificaram respostas positivas à adição de diferentes níveis de plasma animal sobre o desempenho dos leitões mantidos em ambiente com grande contaminação bacteriana ou em sistema de criação convencional, o que sugere que a resposta ao plasma animal é dependente do status sanitário dos suínos. Por outro lado, Muniz ${ }^{22}$ e Nogueira et al. ${ }^{23}$, não observaram aumento do GDP nem alteração na CA quando o plasma foi utilizado na ração dos leitões, o que segundo os autores se deve ao fato de os experimentos terem sido realizados em ambientes com alto status sanitário, se comparados as instalações convencionais.

Dos 21 aos 35 dias de idade a adição de níveis crescentes de OI, em substituição parcial ao LP na ração inicial, não influenciou significativamente $(\mathrm{P}>0,05)$ o GDP, CDR e CA dos leitões.

Os resultados obtidos no presente experimento indicam que a substituição da PB do LP pela PB do OI, em até $45 \%$, realizada através da redução do LP de $23,50 \%$ para $14,45 \%$ e inclusão de $7,62 \%$ de OI, com a correção dos níveis de lactose, possibilitou aos leitões desempenho semelhante no período 1, mostrando que o OI é uma adequada fonte de proteína podendo ser adicionada às rações de leitões no período inicial.

Período 2 (35 aos 48 dias de idade)

Não foram observadas diferenças significativas $(\mathrm{P}>$ 0,05) para os contrastes 2, 4, 5, 6, 7 e 8 sobre o GDP, CDR e CA e para o contraste 1 sobre o CDR.

Dos 35 aos 48 dias de idade, tendo os animais consumido rações com um nível mínimo da fonte de proteína testada no período 1 , observou-se diferença estatística para o contraste 1 sobre o GDP $(\mathrm{P}<0,03)$ e CA $(\mathrm{P}<0,03)$, para o contraste 3 sobre o GDP (P $<0,04)$ e tendência para diferença estatística sobre o $\operatorname{CDR}(\mathrm{P}<0,06)$. 
Os animais que consumiram ração FS no período 1 apresentaram média de GDP superior à média dos demais tratamentos no período 2, e também melhor CA. Estes resultados confirmam aqueles de Li et al. ${ }^{24} \mathrm{e}$ Friesen et al. ${ }^{9}$ que observaram que leitões consumindo ração com nível elevado de farelo de soja, após a desmama apresentaram maior GDP na fase de crescimento, uma vez que estavam mais adaptados fisiologicamente para digerir e aproveitar a proteína de origem vegetal das rações. Concordam também com o relato de Soares et al. ${ }^{10}$, que verificaram que os animais consumindo ração com farelo de soja apresentaram piores GDP e CA, em valores absolutos, dos 21 aos 35 dias de idade, enquanto no período subsequente apresentaram o melhor desempenho.

Não houve diferença significativa $(P>0,05)$ entre as médias dos parâmetros de desempenho dos leitões consumindo rações com níveis crescentes de PS e aqueles consumindo rações com níveis crescentes de OI, em substituição parcial à PB do LP no período 1. Estes resultados sugerem que a utilização de níveis médios de PS e OI proporciona desempenho seme- lhante, devendo-se considerar as análises de regressão dos níveis de PS e de OI, para substituição adequada do leite em pó nas rações de leitões.

O aumento dos níveis de PS na ração dos leitões, dos 21 aos 35 dias de idade, promoveu uma redução linear do GDP, dos 36 aos 48 dias de idade, conforme equação $\mathrm{Y}_{\mathrm{GDP}}=0,4923-0,001359 \mathrm{X}\left(\mathrm{R}^{2}=0,97\right)$ (Figura 2) e tendência para uma redução linear do $\operatorname{CDR}(\mathrm{P}<0,06)$. No entanto, os leitões que consumiram ração com substituição de $25 \%$ da proteína do LP pela proteína do PS, apresentaram, GDP e CDR semelhantes, em valores absolutos, aos daqueles consumindo ração LP.

Os resultados encontrados contrariam os relatos de diversos autores, que detectaram efeito positivo da utilização de plasma sobre o GDP e CDR no período pós-desmama e no período subsequente ${ }^{18,19}$. Já, em outras pesquisas, embora tenham sido observados efeitos positivos da utilização de plasma no período 1 , não foram verificadas diferenças no GDP nem no CDR dos leitões no período subsequente ${ }^{25,26}$.

Dados semelhantes foram verificados por Kats et al. ${ }^{27}$ e Nessmith et al. ${ }^{13}$, os quais observaram redução

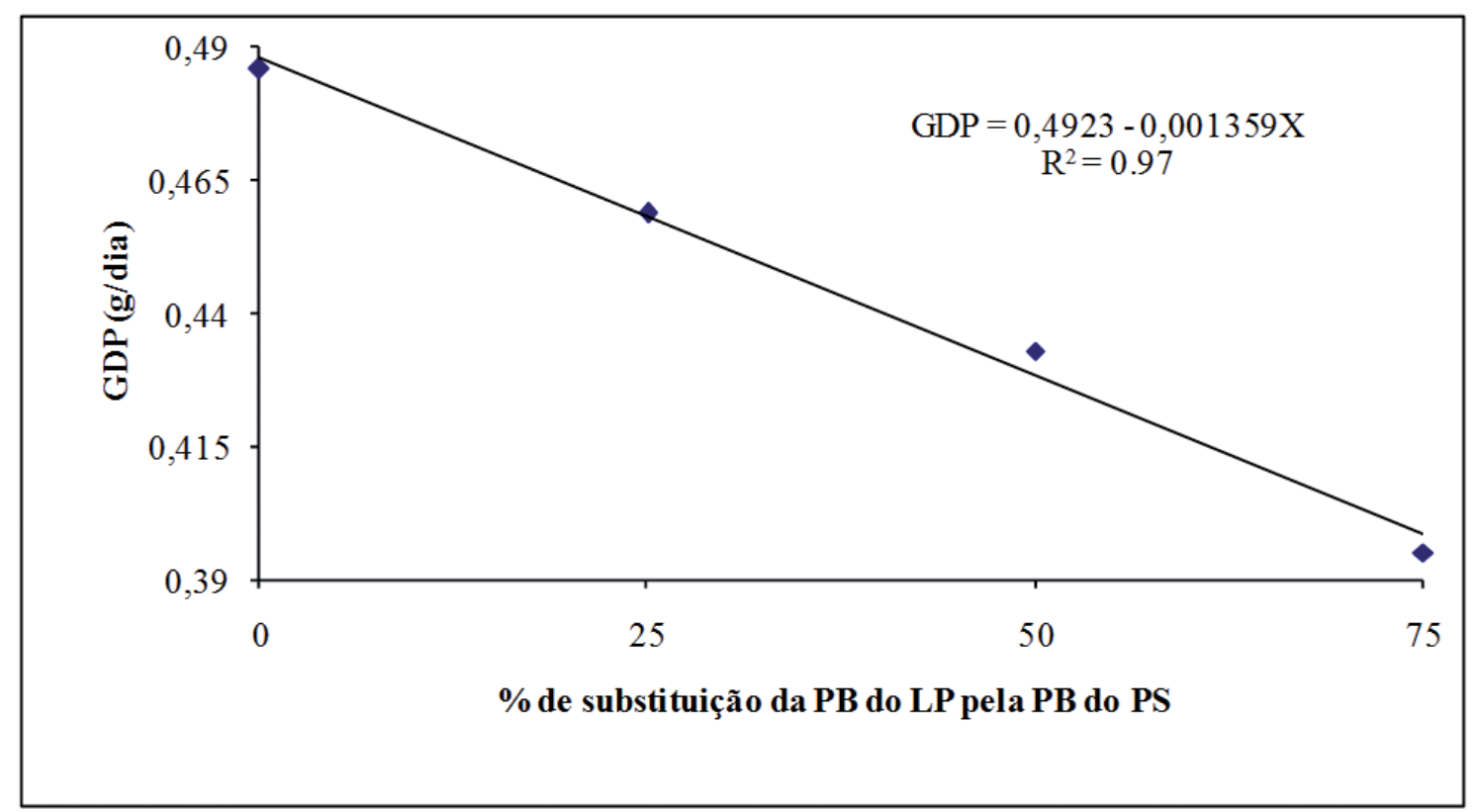

Figura 2 - Níveis de substituição da proteína do LP pela proteína do PS, dos 21 aos 35 dias de idade, sobre o GDP dos leitões dos 35 aos 48 dias de idade 
do GDP no período subsequente, quando leitões desmamados aos 21 dias de idade consumiram rações com níveis crescentes de plasma suíno e lactose, em substituição ao leite em pó. Nestes trabalhos, os CDR não foram influenciados pelos tratamentos.

Embora o aumento dos níveis de PS no primeiro período tenha proporcionado redução linear do GDP e tendência para redução do CDR nos leitões no segundo período, há semelhança ou ligeira superioridade do CDR, em valores absolutos, entre os animais que consumiram rações com o PS substituindo $25 \%$ da PB do LP e aqueles que consumiram LP, confirmando que algum fator associado a palatabilidade $\mathrm{e}$ disponibilidade dos nutrientes interferiu no desempenho dos leitões, quando níveis acima de 2,95\% de PS foram utilizados nas rações.

A utilização de níveis crescentes de OI, em substituição parcial à $\mathrm{PB}$ do LP na ração inicial no primeiro período, não influenciou o GDP, CDR e CA dos animais no período subsequente.

Período 3 (48 aos 138 dias de idade)

Quando todos os animais consumiram as mesmas rações, observou-se diferença significativa para o contraste 3 sobre o CDR $(\mathrm{P}<0,03)$. Para os demais contrastes, $1,2,4,5,6,7$, e 8 , não foram verificadas diferenças significativas $(\mathrm{P}>0,05)$ sobre o GDP, CDR e CA e para o contraste 3 sobre o GDP e a CA.

Os animais consumindo ração com FS, na fase inicial, apresentaram GDP, CDR e CA semelhantes à média dos demais tratamentos no período 3. Estes resultados mostram que a utilização de FS na ração, no período 1, não limitaram o crescimento e possibilitaram aos animais atingirem desempenho, dos 48 aos 138 dias de idade, semelhante ao daqueles que consumiram rações com proteínas do leite, plasma ou ovo. Discordam, por outro lado, de Stairs et al. ${ }^{28}$ que reportaram que produtos lácteos, fornecidos na ração inicial, melhoram o desempenho dos animais na fase inicial e, consequentemente, nas fases de crescimento e terminação.

Os animais consumindo rações com diferentes níveis de PS e OI apresentaram média de GDP, CDR e CA semelhante, dos 48 aos 138 dias de idade.

O aumento dos níveis de PS na ração, no período 1, dos 21 aos 35 dias de idade, promoveu redução linear do CDR na período subsequente, conforme equação $\mathrm{Y}_{\mathrm{CDR}}=2,1805-0,001614 \mathrm{X}\left(\mathrm{R}^{2}=0,77\right)$ (Figura 3).

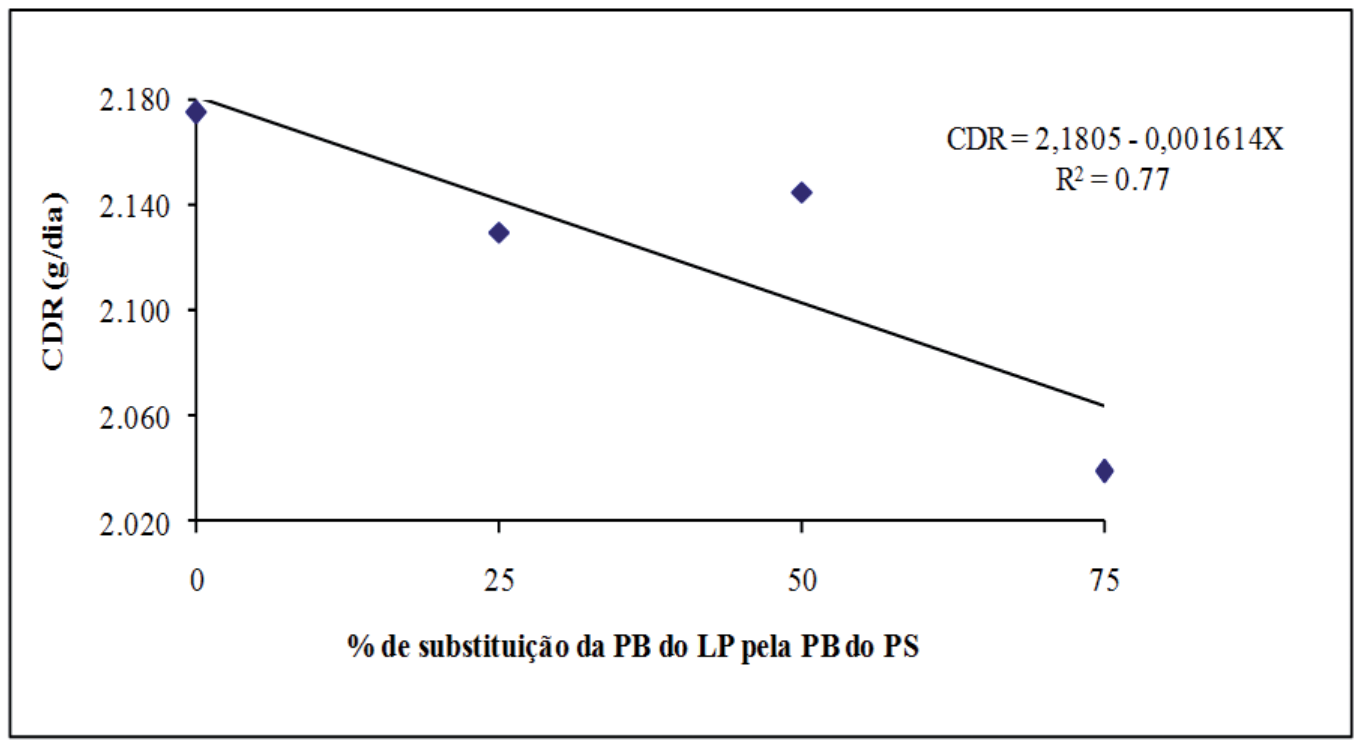

Figura 3 - Níveis de substituição da proteína do LP pela proteína do PS, dos 21 aos 35 dias de idade, sobre o CDR dos leitões dos 48 aos 138 dias de idade 
O GDP e a CA não foram influenciados pela adição de níveis crescentes de PS no período 1, evidenciando inexistência de efeito residual dos tratamentos sobre estes parâmetros. Nos períodos 1 e 2, o GDP (em valores absolutos) dos leitões consumindo ração com PS, substituindo $75 \%$ da proteína do LP, foi 36,70 , 18,7 e $25,46 \%$ inferior ao GDP daqueles consumindo ração LP. No terceiro período, a diferença entre estes tratamentos foi de apenas 3,63\%. Estes resultados concordam com os dados obtidos por Tokach et al. ${ }^{29} \mathrm{e}$ Mahan $^{30}$ que verificaram que suínos com maiores pesos, no final da fase de creche, tenderam a apresentar maior ganho no período de crescimento, mas, não na fase de terminação.

Verificou-se que a redução do consumo de ração no período 3, observada para os leitões que consumiram ração com PS substituindo a proteína do LP em níveis acima de $25 \%$, no período 1 , foi responsável pela redu-

\section{Referências}

1.SOHN, K. S.; MAXWELL, C. V. Effect of source of dietary protein on nutrient digestibility in early weaned pigs. Oklahoma Experiment Station, MP 129, p. 298, 1990.

2.DE RODAS, B. Z.; SOHN, K. S.; MAXWELL, C. I.; SPICER, L. J. Plasma protein for pigs weaned at 19 and 24 days of age. Effect on performance and plasma insulin-like growth factor 1 , growth hormone, insuline and glucose concentrations. Journal of Animal Science, v. 73, n. 1, p. 36-57, 1995.

3.GOODBAND, R.D. et al. General nutrition principles for swine. Kansas State University Agricultural Experiment Station and Cooperative Extension Service, Version 1998. Disponível em: <http://www.oznet.ksu.edu>. Acessado em: 24 maio 1999 .

4.CAMPBELL, J. M.; WEAVER, E. M.; RUSSEL, L. E.; ARTHINGTON, J.; CHI, F. The use of plasma and blood cells in swine feeds. In.: SIMPÓSIO SOBRE NUTRICÃO E MANEJO DE LEITÕES, 1998, Campinas. Anais...CBNA, Campinas, SP: CBNA, 1998. p. 18-32.

5.NRC. Nutrient Requeriments of Swine. 10th ed. Washington, DC: National Academic Press, 1998, 189 p.

6.HANSEN, M. I.; KRONKA, R. N.; THOMAZ, M. C.; TUCCI, F. M.; LIMA, W. A.; LODDI, M. M.; SCANDOLERA, A. J. Composição química, valores de energia e coeficientes de digestibilidade da energia e proteína do plasma suíno e ovo para suínos. Ars Veterinária, v. 20, n. 3, p. 366-371, 2004.

7.EGG PRODUCTS. Nutrient composition. Disponível em: <http://egg-products.html.>. Acessado em: 12 jun. 1999.

8.STATICAL ANALISYS SYTEM. SAS user's guide: statistics. 5. ed. Cary: Institute, 1985. 956 p.

9.FRIESEN, K. G.; GOODBAND, R. D.; NIELSSEN, J. L.; BLECHA, F.; REDDY, D. N.; REDDY, P. G.; KATS, L. J. The ção do GDP, em valores absolutos, destes animais, uma vez que a CA foi semelhante entre os tratamentos.

O aumento dos níveis de OI, na ração dos leitões, dos 21 aos 35 dias de idade não influenciou o GDP, CDR e CA dos leitões no período 3. A semelhança nos parâmetros de desempenho dos leitões consumindo rações com diferentes níveis de OI, em substituição à PB do LP na fase inicial, justifica este resultado.

\section{Conclusões}

Considerando o período da desmama até à terminação as rações inicias podem conter plasma suíno e ovo inteiro, substituindo parcialmente a proteína bruta do leite em pó em 25 e 45\%, respectivamente.

\section{Agradecimentos}

À FAPESP, pelo apoio financeiro.

effect of pre- and post weaning exposure to soybean meal on growth performance and on the immune response in the earlyweaned pig. Journal of Animal Science, v. 71, n. 8, p. 20892098, 1993 .

10.SOARES, J. L.; DONZELE, J. L.; OLIVEIRA, R. F. M. de; FERREIRA, A. S.; FERREIRA, C. L. L. F.; HANNAS, M. I.; APOLÔNIO, L. R. Soja integral processada (fermentada e extrusada) e farelo de soja em substituição ao leite em pó em dieta de leitões desmamados aos 14 dias de idade. Revista Brasileira de Zootecnia, v. 29, p. 1153-1161, 2000.

11.TOKACH, M. D.; PETTIGREW, J. E.; JOHNSTON, L. J.; OVERLAND, M.; RUST, J. W.; CORNELIUS, S. G. Overall pig performance to market weight is improved by adding milk products, but no fat, to the starter diets. Journal of Animal Science, v. 68, p. 377, 1990. Supplement 1.

12.MAHAN, D. C.; LEPINE, A. J. Effect of pig weaning weight and associated nursery feeding programs on subsequent performance to 105 kilograms body weight. Journal of Animal Science, v. 69, n. 4, p. 1370-1378, 1991.

13.NESSMITH JR., W. B.; NELSSEN, J. L.; TOKACH, M. D.; GOODBAND, R. D.; BERGSTROM, J. R.; DRITZ, S. S.; RICHERT, B. T. Evaluation of interrelationships among lactose and protein sources in diets for segregated early-weaned pigs. Journal of Animal Science, v. 75, n. 11, p. 3214-3221, 1997.

14.NESSMITH JR., W. B.; TOKACH, M. D.; GOODBAND, R. D.; NELSSEN, J. L.; BERGSTROM, J. R.; DRITZ, S. S.; OWEN, K. Q.; RICHERT, B. T.; SMITH II, J. W. The effects of substituting spray-dried whole egg from egg grading plants for spray-dried plasma protein in phase I diets. Swine Day, Manhattan, KS.: Kansas State University, 1995. p. 65-67.

15.HARMON, B. G.; LATOUR, M. A.; DURST, J. Spray-dried eggs as an ingredient in diet for sew pigs. Purdue University. 
Swine Day Report. 2000. Disponível em: <http://www.ansc. purdue.edu/swine/swineday/sday00/psd03-2000.html >. Acessado em: 03 fev. 2002.

16. FIGUEIREDO, A. O ovo em pó na alimentação de leitões recém-desmamados. 2002. 61 f. Dissertação (Mestrado em Zootecnia), Escola Superior de Agricultura Luis de Queiroz, Piracicaba. 2002.

17.GATNAU, R.; ZIMMERMAN, D. R. Determination of optimum levels of inclusion of spray-dry porcine plasma (SDPP) in diets for weanling pigs fed in practical conditions. Journal of Animal Science, v. 70, p. 60, 1992. Supplement 1.

18.HANSEN, J. A.; NELSSEN, J. L.; GOODBAND, R. D.; WEEDEN, T. L. Evaluation of animal protein supplements in diets of early-weaned pigs. Journal of Animal Science, v. 71, n. 4 , p. $1853-1862,1993$.

19.SMITH II, J. W.; RICHERT, B. T.; NESSMITH JR., W. B.; NELSSEN, J. L.; GOODBAND, R. D.; TOKACH, M. D. The effect of spray-dried plasma source on starter pig performance. Journal of Animal Science, v. 73, p. 163, 1995. Supplement 1. Abstract.

20.TOUCHETTE, K. J.; ALLEE, G. L.; NEWCAMB, M. D.; PACE, L. W.; ELLERSIECK, M. R. Impact of feed intake and spray-dried plasma on nursery performance and intestinal morphology of weaned pigs. Journal of Animal Science, v. 75, p. 198, 1997. Supplement 1.

21.BERGSTROM, J. R.; NELSSEN, J. L.; TOKACH, M. D.; GOODBAND, R. D.; DRITZ, S. S.; OWEN, K. Q.; NESSMITH JR., W. B. Evaluation of spray-dried animal plasma and select menhaden fish meal in transition diets of pigs weaned at 12 to 14 days of age and reared in different production systems. Journal of Animal Science, v. 75, n. 11, p. 3004-3009, 1997.

22. MUNIZ, M. H. B. Plasma bovino desidratado na dieta de leitões desmamados precocemente. 2000. 33 f. Dissertação (Mestrado em Zootecnia), Faculdade de Medicina Veterinária e Zootecnia, UNESP, Botucatu, 2000.
23.NOGUEIRA, E. T.; TEIXEIRA, A. O.; LOPES, D. C.; ROSTAGNO, H. S.; SANTIAGO, L. L.; AMARAL, A. M. Utilização de plasma em dieta de leitões desmamados aos 21 dias de idade. In: REUNIÃO ANUAL DA SOCIEDADE BRASILEIRA DE ZOOTECNIA, 38, 2001, Piracicaba. Anais.. Piracicaba, SP: SBZ, p.843-844, 2001.

24.LI, D. F.; NELSSEN, J. L.; REDDY, P. G.; BLECHA, F.; KLEMM, R.; GOODBAND, R. D. Interrelationship between hypersensitivity to soybean proteins and growth performance in early-weaned pigs. Journal of Animal Science, v. 69, n. 10, p. 4062-4069, 1991.

25.COFFEY, R. D.; CROMWELL, G. L. The impact of environment and antimicrobial agents on the growth response of early-weaned pigs to spray-dried porcine plasma. Journal of Animal Science, v. 73, n. 9, p. 2532-2539, 1995.

26.JENNINGS, N. T.; AZAIN, M. J. Effects of dietary plasma protein on growth and feed intake of weanling pigs. Annual Report, USA Animal \& Dairy Science. 1995. 6 p. Disponível em: <http://www.ads.uga.edu/annrpt/1995/95_272.htm>. Acessado em: 04 fev. 2002.

27.KATS, L. J.; NELSSEN, J. L.; TOKACH, M. D.; GOODBAND, R. D.; HANSEN, J. A.; LAURIN, J. L. The effect of spray-dried porcine plasma on growth performance in the early-weaned pig. Journal of Animal Science, v. 72, n. 8, p. 2075-2081, 1994.

28.STAIRS, J. T. F.; TOKACH, M. D.; PETTIGREW, J. E.; WILSON, M. E. Milk products in starter diets improve subsequent pig performance. Journal of Animal Science, v. 69, p. 116, 1991. Supplement 1.

29.TOKACH, M. D.; GOODBAND, R. D.; NELSSEN, J. L.; KATS L. J. Influence of weaning weight and growth during the first week post weaning on the subsequent pig performance. Kansas State University, Kansas. Swine Day Report. p. 19-21, 1992.

30.MAHAN, D. C. Effect on weight, split-weaning, nursery feeding programs on performance responses of pigs to 105 kilograms body weight and subsequent effects on sows rebreeding interval. Journal of Animal Science, v. 71, n. 1, p. 1991-1995, 1993. 